Regarding their attendance to work, let me show you an example of Negano plant. The slide shows the monthly attendance during the year of 1966. Attendance rate is a little decreased in February and March. But during the rest of the year it shows more than 90 per cent. with average rate of 93 per cent. The rate of attendance can be said to be better than that of some plants with normal healthy workers.

Recurrence of bedsores represents the highest percentage of absenteeism. However, it was less than five among an average of 45 attendances per day. As this plant is situated at the mountainside and in a colder area, frostbite also causes them to leave their post during wintertime from November to March. The cases of frostbite were I.5 persons at daily average. Urinary flare-ups were few; the most frequent in a month were $3 \mathrm{I}$ in total.

Four men left the plants in a year because they changed their jobs.

Fatigue through work was examined in 17 paralysed, in the form of questions and answers in each patient. Nine out of them had fatigue after work, but there was only one who answered that his fatigue lasted during the following day. The remaining eight patients did not feel any fatigue through eight hours' labour. Those who have lesions of higher level of the spinal cord complained more of fatigue. Among I 2 patients who have lesions below the ninth thoracic segment, five complained of fatigue and seven did not. It can be concluded that the level of the lesion of the spinal cord has some relation to fatigue through labour.

The last problem is wages for them. At present their wages vary between I 8,000 yen and 25,000 yen per month. This is a little higher than the average juvenile labourer earns in Japan.

Up to date much money has been spent for the special facilities and welfare for the paraplegic disabled. Therefore, the actual wages are relatively low. However, their total income is not low, since the majority of them have received an accident and invalidity pension. It is the general opinion that employment of these disabled labourers is becoming aware to the public, the more so since the present industrial situation represents a big problem because of lack of labourers in comparison with the surprising development of industry.

Those three plants mentioned above have attracted public attention and we expect such plants will be increased in the near future.

\title{
ORGANISATION OF SPINAL UNITS
}

By Phillip Harris, F.R.C.S.E., F.R.C.P.E., F.R.C.S.(Glas.), F.R.S.E.

Department of Surgical Neurology, Western General Hospital; the Royal Infirmary, Edinburgh; and the Spinal Unit, Edenhall Hospital, Musselburgh, Scotland

Most new ideas in medicine are not accepted immediately, and the demonstration by a few medical pioneers beginning some 20 years ago, that paraplegic patients could be successfully nursed, treated medically and fully rehabilitated was no exception to this rule. However, the general standard of care, resettlement and 
return to society of these patients has steadily improved and this is being taken up by hospitals in many parts of the world. Medicine owes a great debt to the lead and inspiration of someone like Sir Ludwig Guttmann, who has overcome so many seemingly unsurmountable problems to achieve the remarkable and nowadays indeed expected results in the management of paraplegic and tetraplegic patients. The advent of major wars, and high-speed road traffic accidents, and the development of specialties such as neurosurgery, orthopaedic, urological and plastic surgery, have created new interest in the prevention and management of the injured (Munro, I945; Guttmann, I953, I962; Bors, I956; Kahn, I959; Rossier, I963; Geisler et al., I965). Spinal units such as, in this country, the National Spinal Injuries Centre, Stoke Mandeville Hospital, have played a most important part in the successes so far obtained, but there is much more still to be done in the way of development and research, education and training.

The term 'Spinal Service' is preferred to 'Spinal Unit', and when organising such services it must be appreciated that we are not only taking into account the present situation but also planning for the future. One person cannot be expected to be an expert in all or even most of the many medical and other aspects of these patients, and therefore a closely knit complex of the major specialties is essential and, indeed, a re-integration of such specialties is necessary. The size of the problem is not well known for any particular type of severe spinal lesion, and in Britain alone there are many thousands of patients with such a condition. The nature and level of the neural involvement is also changing, as is seen in the large number of children with myelo-meningocoele who now survive beyond the first year of birth; and in cervical injury often now supplanting dorso-lumbar injury as the commonest site for damage in accidents.

\section{TRAUMATIC LESIONS}

Severe spinal injury may result from civilian accidents, and, unfortunately, wars still occur and many patients are appearing, some with penetrating spinal injuries. These patients should initially be admitted to a suitable central accident unit which should be part of a general hospital containing essential special services such as surgical neurology, orthopaedic surgery, urological surgery, plastic surgery, paediatric surgery and internal medicine (Accident Services Review Committee, I961, I965; French, 1964; Robinson, 1966). Fortunately industrial accidents, and in particular mining accidents, are much less common nowadays, certainly in Britain, but with 'break-neck speeds', road traffic accidents and also falls from heights and diving accidents are producing serious injuries to the cervical spine, and indeed in many centres dealing with spinal injury patients, admissions of cervical cases are almost common or even more common than those with injuries to other parts of the spine. In addition, associated injuries are more common nowadays from high-speed accidents and multiple injuries. These patients require proper first-aid care, and they should be transported as quickly as possible to the nearest accident service, where any immediate initial hospital treatment will be carried out, in particular regarding airway, respiratory functions and haemorrhage; and 24-hour facilities for special radiological investigations and for special operative treatment are necessary. It is quite uneconomic and unrealistic to plan for the investigation and treatment of such patients in the acute 
phase in poorly equipped and poorly staffed centres or hospitals that do not have the comprehensive facilities such as are now understood to be necessary. Spinal cord injury patients should be referred to the specialists concerned with such a service within 24 hours of injury so that a correct

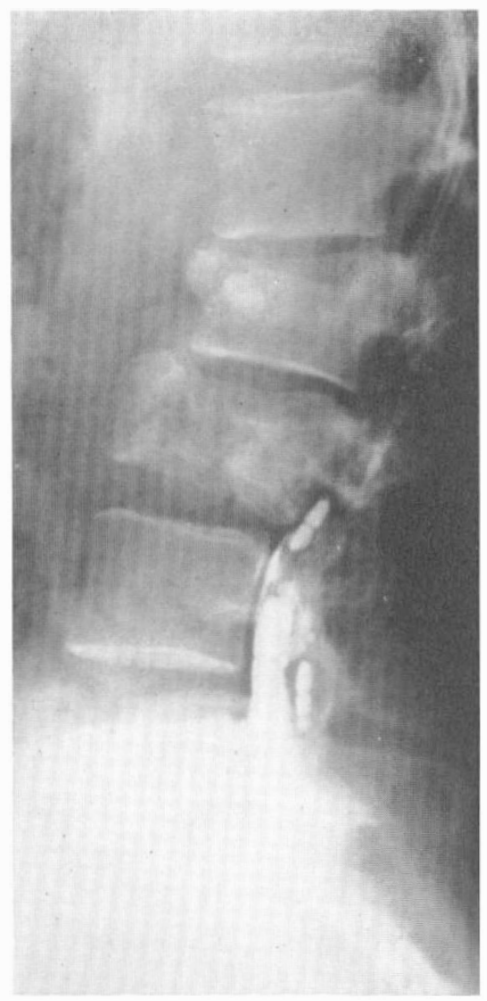

FIG. I

Myelogram in patient with fracture of lumbar 2 and 3 vertebrae (see text). diagnosis may be made and correct treatment instituted. Figure I shows the myelogram of a patient who had not developed the degree and speed of recovery to be expected after a traumatic cauda equina lesion. Myelography demonstrated the presence of dural and arachnoidal tears and arachnoiditis. These findings were confirmed at operation and many roots of the cauda equina were lying partially in the spinal epidural space and were matted together. Earlier myelography and operation is indicated for this type of case (Harris, 1965). In the Department of Surgical Neurology in Edinburgh, 45 per cent. of admissions are patients with lesions of the spinal cord and nerve roots, including spinal injuries, disease of the cervical and lumbar discs, spinal neoplasms, epidural abscess, spinal tuberculosis, and spina bifida. A surgical neurology unit will have the special diagnostic and therapeutic facilities necessary for the study and treatment, therefore, of all types of spinal cases, and such a unit is a vital part of an accident service (Harris, 1963). A 'flying squad system' (Gregg \& Wilmot, 1964) is an interesting conception, but it does not have a place in the routine care of spinal injury patients. Meirowsky (1965) describes the plan for the care and transport of spinal cord injury patients in the Korean War: first echelon in helicopters take casualties to Mobile Neurosurgical Teams attached to Mobile Army Surgical Hospitals; second echelon: air transport to a Neurosurgical Centre in the Communications Zone; third echelon: to Paraplegic Centres in the Zone of the Interior.

\section{NON-TRAUMATIC SPINAL LESIONS}

These are very common and indeed are more common than traumatic lesions of the spinal cord and nerve roots. They include spina bifida with neurological involvement, transverse myelitis, vascular lesions of the spinal cord and roots, and disseminated sclerosis. It has been estimated that about 200 children are born in Scotland and some 2500 children in England and Wales each year with spina bifida and severe neurological involvement. Referring to these patients, Smithells (1965) states, 'this is the size of the challenge'. Patients with serious non-traumatic disturbances of the spinal neural elements require the same facilities 
as those with lesions from trauma, and after initial study and treatment in the special unit concerned, be it medical or surgical neurological, internal medicine or paediatric, they require the same medical and surgical and nursing expertise that is necessary for patients with traumatic spinal lesions. Eventually some of those with non-traumatic spinal lesions will be transferred for continuing care to a spinal rehabilitation unit. In a report on the National Spinal Injuries Centre (Guttman, I962), 67 per cent. of the first 2000 patients admitted by I959 had had a spinal injury, and 35 per cent. had non-traumatic lesions.

\section{SPINAL REHABILITATION UNITS}

Spinal rehabilitation units may either be part of a general rehabilitation hospital or be closely associated with a general hospital. They should work in very close liaison with special services in a main teaching hospital, such as surgical and medical neurology, and orthopaedic and plastic surgery, and if possible should be an essential part of a main medical centre and medical school. Special investigations and major operative treatments are carried out in the special unit concerned in the main general hospital, the patient being admitted there for these investigations and treatments and then returning as soon as possible to the spinal rehabilitation unit. In the latter unit the tempo is different, the stress being on rehabilitation and intense activities for resettlement. It requires proper nursing, and attachment to a Nurses Training School is advisable. Full rehabilitation services, facilities for vocational training, a swimming pool, bio-engineering facilities and a school for children are necessary. Wards, toilets, bathrooms, day-rooms, dining-rooms, lounges, Section V (private) accommodation, out-patient facilities, laboratories, staff rooms, an information centre, rooms for the Medical Social Workers and Disablement Resettlement Officer, examination rooms, seminar and lecture rooms, an operating theatre suitable for minor surgical investigations and treatments, and simple radio-diagnostic facilities must be available. The geographical situation will require to be taken into account, and if possible the unit should be near various city amenities such as shops, hairdressing salons, and a cinema. A sheltered workshop is required, as are stay-over beds for relatives and for visiting doctors; and a special dietetic service. In addition, proper facilties for both clinical and laboratory research are necessary. It requires a consultant in administrative charge and a staff of doctors, nurses, physiotherapists, occupational therapists, remedial gymnasts, secretaries, etc. The size of the spinal rehabilitation unit would depend on several factors, but in Scotland it is felt that there should be two such units, one in the West, centred in Glasgow, and one centred in Edinburgh for the East. They would each have between 50 and 70 beds. In the grounds there should be space for sports activities, in particular for archery, basket ball, bowling and various field events. Disease indexing and efficient records, which can be put on to punch cards for regular yearly analysis and for use by those involved in clinical and other research, are necessary. Many of these facilities require to be specially designed for paraplegic and tetraplegic patients, others can be used in common with other patients in the rehabilitation hospital. It is important not to entirely segregate spinal from other groups of disabled patients requiring expert rehabilitation and resettlement. 


\section{INTERCHANGE OF KNOWLEDGE}

With the inevitable development of more specialised and more sophisticated special units and services in medicine and surgery, it becomes essential that the knowledge gained and the experitise available is made use of by others not so closely involved with these special services. This is well illustrated in a service for patients disabled by serious spinal injury or disease. What is required is education, and such services should be used for the regular training of undergraduate and post-graduate doctors and for part of the training of those who wish to become specialists, such as neurosurgeons, urological surgeons or orthopaedic surgeons; for the training of nurses, physiotherapists, occupational therapists and others who would obviously benefit from the experience that can only properly be obtained in such a service. Seminars, refresher courses and formal lectures are all necessary. The activities of a spinal service should be so arranged that an interchange of ideas is achieved at meetings and through journals, specialised and general.

We can be proud of our International Medical Society of Paraplegia and its fournal. We cannot only hear of each other's experiences and ideas and debate them, sometimes hotly, but also most of us take every opportunity to inform our associates in other branches of medicine, nursing and rehabilitation of new procedures and developments in spinal neural injury and disease.

\section{SUMMARY}

In the past 20 years great advances have been made in the medical and nursing management, rehabilitation and resettlement of patients with serious spinal neural disease and injury. Special spinal units have played an important part in these advances.

A change is occurring in the type and site of serious spinal lesions, and more intensive and sophisticated specialist services have become available for their diagnosis and treatment.

Preference is given to the term 'Spinal Service'.

Patients with traumatic lesions require admission to a central accident unit, part of a general hospital, and then as soon as possible are transported to a spinal rehabilitation unit. Special planning is required for war casualties.

Non-traumatic spinal lesions are particularly common, especially those due to congenital malformations of the spinal cord.

The spinal rehabilitation unit should either be part of a general rehabilitation hospital or a general hospital. Full facilities are required, including those for teaching and research.

Interchange of knowledge in the management of patients with serious spinal disease between all those who may be concerned with such patients is essential.

\section{REFERENCES}

Accident Services Review Committee. Interim report I96I; Second report 1965.

Brit. med. Ass. House, Tavistock Square, London, W.C.I.

Bors, E. (1956). Bull Los Angeles neurol. Soc. 21, 105. 
DotT, N. M. (1967). Personal communication.

FRENCH, P. R. (1964). Clinical Surgery, pp. I-I3. Eds. C. Robb and R. Smith. London: Butterworths.

Geisler, W. O., Wynne-Jones, M. \& Jousse, A. T. (1965). Proc. IIIrd int. Congr. Neurol. Surg., Copenhagen. Excerpta Medica I.C. Series, No. I IO, pp. 347-352.

GReGG, T. M. \& WILmot, C. B. (I964). Int. F. Paraplegia, 2, I5.

Guttmann, L. (1953). Medical History of the Second World War: Surgery. Ed. Z. Cope. London: H.M. Stationery Office.

GutTMAnn, L. (1962). Mth. Bull. Minist. Hlth Lab. Serv. 21, 60.

HARRIS, P. (I963). Spinal Injuries, pp. IOI-I02. Ed. P. Harris. Royal College of Surgeons of Edinburgh.

Harris, P. (1965). Proc. IIIrd int. Congr. Neurol. Surg., Copenhagen. Excerpta Medica I.C. Series, No. I IO, pp. 347-352.

KAHN, E. A. (I959). F. Bone ft. Surg. 4I-A, 6.

KERR, W. G. (I967). Personal communication.

LAMB, D. W. (1967). Personal communication.

Meirowsky, A. M. (1965). Neurological Surgery of Trauma, pp. 289-290. Ed. A. M. Meirowsky. Department of the Army, Washington, D.C.: Office of the Surgeon General.

MunRo, D. (1945). Clinics, 4, 448.

Newsam, J. E. (I967). Personal communication.

Robinson, J. S. (1966). Proc. R. Soc. Med. 59, I293.

Rossier, A. (1963). F. int. Coll. Surg. 39, 225.

Smithells, R. W. (1965). Proceedings of a Symposium on Spina Bifida. National Fund for Research into Poliomyelitis and Other Crippling Diseases. Vincent House, Vincent Square, London, S.W.I.

\title{
ON THE IMPORTANCE OF INDIVIDUALISATION OF SPINAL UNITS IN HOSPITAL ORGANISATION
}

\author{
By VICTOR GASPAR, M.D. \\ Urological Department of the Military Hospital in Oporto, Urologist to the \\ Francisco Noronha Hospital (Recuperation Centre for the Physically \\ Disabled), Portugal
}

OuR views are based on the experience which, as urologists at a recuperation centre for the physically disabled, we have acquired regarding the treatment of paraplegic patients.

All the patients had been sent to us from diverse hospitals, being referred usually from neurological or orthopaedic departments.

We have dealt with 65 paraplegics over a five-year period; in 7.5 per cent. of these the paraplegia was the result of non-traumatic lesion affecting the spinal cord; in the remaining cases the paraplegia succeeded a spinal injury. Only a minimal percentage $(5 \cdot 6)$ reached this centre within the first month following the accident, and of the remainder, 54.3 per cent. arrived here after more than three months. Almost all of them were suffering from complications which endangered their rehabilitation.

After investigating the causes of and classifying the frequency of those complications the results were as follows: 